\title{
MJN PRE-CLINICAL YEAR MEDICAL STUDENT'S EXPERIENCE TOWARD SIMULATED PATIENT ENCOUNTER: A QUALITATIVE STUDY
}

\author{
Goh Lay-Khim, Yee Bit-Lian* \\ International Medical University, Malaysia \\ *Corresponding Author's Email: bitlianyee@imu.edu.my
}

\begin{abstract}
Introduction: Many universities have been utilizing simulated patient (SP) programme for more than a decade for teaching sessions and simulation activities as well as Objective Structured Clinical Examination (OSCE), however the pre-clinical year medical student's experience toward the SP encounter yet to be explored. The aim of the study was to explore the pre-clinical year medical student's experience towards the SP-based simulation session. Methods: Total of 6 participants were recruited for a focused group interview, with the inclusive criteria of minimum enrolled into the medical program for more than a year. The interviewer used a list of guide question to explore both the positive and negative SP encounter experience during teaching and learning session as well as OSCE. A combination of manual and computer software Program was used for data management and analysis. Results: Three main themes and eight sub-themes have emerged. The first theme was Simulated patient as an effective learning tool, with the sub-themes of SP attitude and realism; second theme was Fairness, with the sub-themes of Appropriateness respond to student, Calibration of SP performance and Consistency; the third theme was Feedback from Simulated patient, with the sub-themes of Feedback on student's skill, Feedback on student social intelligence and Poor feedback skill. Conclusion: Student perceived that SP was proved as an effective learning tool only if the SP was able to portray a real patient role as well as able to demonstrate effective feedback skill. Moreover, standardization of the SP role portrayal and SP feedback influenced the fairness along the students' journey, especially during OSCE. Training SP for both realistic portrayals of the character and feedback is essential to optimize an SPbased simulation session.
\end{abstract}

Keywords: Medical student; Experience; Simulated Patient; Simulated Patient Encounter

\section{INTRODUCTION}

According to Onari, Pampaloni \& Multak (2012), simulated patient (SP) is defined as a trained individual to portray role of a patient with various health associated conditions. Nestel \& Bearman (2015) refers the terms SP to a healthy individual that trained to portray a patient. Beigzadeh, et al., (2016) identified SP is a lay person who simulates as a real patient based on differ levels of training. Combination of above, SP can be defined as a lay person that simulates to portray a role of patient with health-related conditions based on varying levels of training.

Research had confirmed that training sessions with SPs enable Medical students to reinforce knowledge, develop communication skills, enhance clinical skills as well as cognitive aspect of clinical competence such as decision-making and clinical reasoning, practice interviewing skills, increase awareness of ethics, enhance confidence (William \& Song, 2016; Wisborg et al., 2009; Gamble et al., 2016; Quail et al., 2016). Studies have reported Medical school in Ireland, Scotland, Belgium, Netherlands, Australia, Canada, Switzerland, United Kingdom been using SPs to train Medical students in communication skills and physical examination skills. Majority of the Medical schools emphasized the integrated physical examination and communication skills. William \& Song (2016) identified 'hybrid simulation' to further enhance the development of clinical skills with emphasis on communication competence. Hybrid simulation is regarded as a method that integrate SP and mannequins (William \& Song, 2016), for example, using an SP and an arm model to teach, practice or assess both clinical skills and communication skills. 
A comparison study done in 2012 by Bressmann and Eriks-brophy on of speech-language pathology of students' learning experience about managing difficult patient using SP methodology and group presentation and role play. The quantitative result found that there were no significant differences in grades between two group of students regarding the learning experience $(p=0.367)$, thus it cannot be concluded that SP methodology contribute more experience in speechlanguage pathology in students' learning. However, quantitative data showed that student appreciated the opportunities to try the Six Category Intervention Analysis strategies with SP and expressed that the interaction with SP added interest to the learning experience. Another study done by Bokken et al., (2009) on a SP program that involved adolescent as SP in teaching Medical students on communicating sensitive consultation such as contraceptive and sexuality issue. The facilitators remarked that involving adolescent SP addressed interesting aspect of communication, for example, dealing with peers professionally and asking questions about or discussing sexuality. Both studies indicated that SP methodology improve student learning experience. Another comparison study on longitudinal SP program and single case SP program by Bokken et al. (2009) showed that students were neutral about learning communication skills from both SP methodology.

A systemic review of children and adolescents simulated patient paper concluded that SPs had impact on all health care education programs positively regarding confidence (Gamble et al., 2016). Another study done by Quail et al. (2016) supported involvement of SPs that increased student's confidence. The result of the study showed that regarding undergraduate speech pathology, students self-perceived that the confidence level had significantly increased post interaction with SP for a week $(p=<0.0125)$. However, Bressmann \& Eriks-brophy (2012) expressed the concern of training with SP may develop an unrealistic feeling of confidence, pertaining to the scenario when students are able to manage a difficult SP. The aim of this research is to explore the experience of pre-clinical year medical student's experience toward Simulated Patient encounter in a private Medical University.

\section{METHODOLOGY}

This was a descriptive qualitative study, using purposive sampling method. The participants were selected based on the inclusive criteria of the students that is must be willing and voluntary to participate, as well as the students must have more than a year experience involving in SP-based simulation activities in Clinical Skill and Simulation Centre and have interacted with any SP in at least one Objective Structure Clinical Examination (OSCE) prior to the interview session. A total five participants were involved for a focused group interview and one student was involved in one-to-one interview session. A list of guided questions used to assist the researcher to explore the experience of participants towards Simulated Patient-based simulation session. The interview was audio-recorded, and transcript recorded manually, followed by a combination of manual coding and computer software Program (Qualitative Data Analysis Miner) was used for additional data management and analysis.

\section{RESULTS}

Total of six students were involved in two interview sessions; one focused group with five students and oneto-one interview. Three students have completed their pre-clinical year, one currently in Semester five (final pre-clinical year), one in Semester four and one in Semester three. The participants learning experience with SP ranged from one and a half year to three years. Three themes emerged from both focused group and one-to-one interview with students' group. The themes were Simulated patient as an effective learning toolcoded the most, followed by Fairness, and Feedback from simulated patient.

\section{Simulated Patient as an Effective Learning Tool}

Participants concluded there are two main elements of SPs that enhance student learning experience, i.e. realism and SPs' attitude.

\section{Sps'Attitude}

Most of the participants appreciated the interaction with SPs. Student identified that SPs were serious about their learning session, understanding their weakness, cooperative and patient with them.

"We feel this is very funny ... they make it more serious and real." - Student 1

"They are pretty good, no one really very serious, scream to us... They know we are still learning, so if we make mistake, they are ok with it. " - Student 2

"Just they are very cooperated. Like the one during palpation ... because our hands are super cold, although it is not comfortable for them, but then they still take it." - Student 3 
"They are really patient with us. For history taking, $S P s$, they memorize their script well, really helps us a lots. "-Student 4

"When we do the palpation of abdomen, then they just lie there quietly for us to press. " - Student 5

On the other hand, all participants observed that SPs who misbehave had negative impact on their learning experience as well as performance. Students referred misbehavior as inaccurate information given, show no interest in conversation, sleeping during class, and judgmental toward students' performance.

"I think she read a wrong script. It took several minutes for me to calm down ... and I try to calm her down by helping her see through the situation, ..." - Student 5

"When they go really like they are not even interested in listening to what we say, and then yawned, to me it was a throw back ...." - Student 3

"Ya, is kind of bad experience, ...they fall asleep then it defeats the purpose."-Student 2

"Ya, they judge us, ... then everyone will watch you, and then there is an outsider to judge you, so always get nervous. "- Student 1

"The SP may miss something or tell the wrong thing then everything just messed up." - Student 4

"If the SPs, they go haywire in those sessions, then I don't think will be helpful." - Student 6

\section{Realism}

All participants observed that realism had influenced learning journey of the student. The realism can be defined into two aspects: acting skill and correlated with real patients. Majority comments were regarding realism of SP portrayal that enriched their learning experience by improving their communication skills and questioning skills.

"My SP was a pregnant lady, the mother came in because she saw the report... she was like asking why I can't show all the result and all, and they keep asking the same question, although I was annoyed, ... then we have to explain patiently, but they acted really well." -Student 4

"I will feel very excited for the class, because I will know that there a realistic patient there, so I would be asked question and its help with my history taking skill." - Student 5

"When we talk, ... say like simple English and it is good training as well for us to talk to stranger, ... ya, like real exposure, so next time when we go to practical phase and it will be easier for us to interact with patient." Student 3

"I try in out in the actual clinic with the actual patient, for me kind of help, I was just thinking about how do to take history of someone." - Student 2

"...I remember having the same patient for 2 days, but his acting skills are quite intact. So, in a way ...the person kind of familiar with,... you feel more comfortable, and you are at ease, ... Ya, so, ya, thing really depend on the acting skills of patient." - Student 6

“..., but actually, many of them have that condition, especially for the common diseases, like diabetes and hypertension, and asthma, this kind of common disease, a lots of SP actually really have." - Student 1

Minority comments about realism impacted the sessions negatively. Inaccurate portrayal of role may mislead students' clinical judgment.

"Their acting might mislead us to answer the wrong answer. For example, like empathy session, that one is very subjective ..., if the SP himself never act probably, then if student react appropriately then it should be fine already, it shouldn't be like, oh, you have not enough empathy, who know is because the SP not enough 'kelian'(pitiful in Chinese). '-Student 1

\section{Fairness}

Students expressed issues pertaining to fairness in three different aspects: appropriateness respond to student, calibration of SP performance, and consistency of SP performance.

\section{Appropriateness of responds to student}

Four participants commented on appropriateness of SPs' respond toward student during classes as well as OSCE. Three students expressed SP response inappropriately toward student, such as interrupted student's flow, difficulty in communication, over releasing information, and accelerated physical sign.

“... I was just trying to present whatever she told me, but then during the presentation itself, I was told that I misinterpreted whatever she said ... in many ways I feel offended." - Student 6

"I don't know if the patient really has hearing problem or he was acting to have hearing problem, but I spend almost like one to two minutes trying to talk to 
him, ... then I have to go to his ear and talk to him. ...."Student 1

"One session is about alcohol history, then the story of the $S P$ is very very long, ... the SP kept on talking, ... I can't stop it, so I just listen, ... by the time she finished talking, and my turn to talk and I have less time to finish all of my questions that I needed to ask..." - Student 3

"...give us unnecessary accelerate action." Student 4

Two volunteers appreciated the appropriateness of respond from SP. The students perceived that appropriately holding and releasing information which correspond with students' question regards as appropriate respond.

"We are doing the right way only they tell us the correct answer, so I think for history wise is good that got SP.”-Student 4

"He was able to answer, sometimes although he was a bitconfused ..." - Student 5

\section{Calibration of SP performance}

Four students expressed concerned regarding calibration of SP performance which impacted on the fairness for both classes and OSCE. Students felt that calibration of SP performance should include training for accuracy of role portrayal, appropriately holding and/or releasing information, and feedback skill as well as prohibit prompting. Some thought it was merely luck to have helpful SP.

"...so we have to palpate the liver, then according to some of my friends, they said the patient was having terrible pain, ... but then personally for me, when I was pressing, he wasn't doing anything, he was giving some expression of pain, ...Different students get different reaction, this one I think is a bit not fair." - Student 1

"Some of them (SP) will give more thing to you, ... but some of them, they are like just stick to what you ask ... "-Student 4

"There are cases where sometimes in exam, the $S P$ will try to help you because they are nice, because they try to hint you, so whoever that get those SP will be lucky, but then since OSCE ... then is not fair.." Student 1

"Because some people they have better SP, they have better experience, some might not have a really good SP, so their experience is a bit lesser, so, it is based onluck." - Student 2

"Our first recording session, ... I think this particular SP I had, I think she read a wrong script, so she appeared as an angry SP, so at that time, I was just Semester one."'-Student 5

\section{Consistency of SP performance}

Three participants observed that disrupted consistency of SP performance affected the fairness of OSCE. Oxford Living Dictionaries (2018) defined consistency as the quality of achieving a level of performance which does not vary greatly in quality over time. Consistency of SP performance referred to the individual SP to maintain the quality of performance over time, such as portray of clinical sign, and amount of information released.

"He really exaggerate a lots, ... because we were told to try to persuade the patient,..." - Student 1

"When I ask her about whether she have any family member, then ask her whether she is married, then she said no, and then when I ask, so obviously she said no, so didn't went into pregnancy history, but then for other people, she said yes to them, that is the same patient. ..." - Student 4

"At least have the proper reliability... you answer people like you answer for everybody." - Student 3

While, one student expressed appreciation of SP retained consistency during OSCE.

"They are like repeatedly getting a tummy examination, then like will have six students coming in with cold hand to feel around their stomach, some of them will act really well." - Student 4

\section{Feedback from simulated patient}

The students commented on the SP feedback skills, in which focused on feedback on student social intelligence, feedback on student skill as well as poor feedback skill.

\section{Feedback on student skill}

Most of the participants expressed SP gave comment about students' skill, such as physical examination skill and questioning skill.

"Most of them just give me a lots of feedback, grateful, like ...I tap on my finger during percussion, I accidentally tap on them,..." - Student 2

"When we ask like some sexual question, regarding 
infertility or something, all the sexual issue, they will tell us how the patient feel when we ask question, because this is a very sensitive issue." - Student 3

"Like how we would rephrase the sentences better." - Student 4

\section{Feedback on student social intelligence}

Two of the six students commented on the content of SP feedback were focused on social intelligence (empathy, verbal and non-verbal communication skill).

"They normally say for history is how you sit in front of patient, your posture with them, whether it is like to close to them." - Student 4

"He was watching my expression, by eye contact, the content ... like when he walked in, I can stand up and come and help him, bring him to the seat or maybe when he is coughing, I can like go get some tissue paper for the SP."-Student 1

\section{Poor feedback skill}

Two out of six volunteers expressed that they were not satisfied with the SP feedback skill, for example general, non-specific feedback.

"Although (the feedback) is not very helpful all the time." - Student 5

"Not all the SP will give us feedback, some of them justya, is ok, is not bad." -Student 1

\section{DISCUSSION}

Student perceived that SP acted as an effective learning tool only if the SP are able to portray as a real patient during the simulation sessions and provided effective SP feedback. Moreover, standardization of the SP role portrayal and SP feedback influenced the fairness along the students' journey, especially during OSCE.

\section{SP Portray as a Real Patient}

While learning the students took parts in the conversation and interaction between the SPs, which gave the students a feeling of talking to an individual who had specific condition before they competently treat a real ill patient. Through conversation, learners are able to develop adequate communication skill and medical interviewing skill to apply in the actual clinical setting. Smith et al., (2015) expressed that the students were engaged with the experiential learning and were engaged as if they were in a real clinical encounter which connected the scenario with the real work meaningfully through realistic portrayal of a patient role because the trainees believed they were dealing with a real patient. The student group of participants identified that by accelerating the symptoms, over release the information, not portray of emotional, low tone of voice, holding back of information decreased in realistic portrayal of a patient role. In simple, the students perceived realistic portrayal of the role as appropriate in responding to student, including both verbal and nonverbal response. Smith et al., (2015) emphasized that SP performance must be realistic in both clinical details and the human experience. Therefore, the students benchmarking for quality SP performance are accurate with respect to medical content as well as natural reaction toward students. The SPs work are not only concerned with the accuracy of every single information that are conveyed to students, but also in what way and how much to convey as well as improvise answer according to the students' question, which was not stated in the script.

\section{Effective SPfeedback}

Feedback can be very powerful if done well (Brookhart, 2017). The learner gain insight of their behaviour, strengths and areas for improvement through feedback (Dudley, 2012). The role of the SP feedback was to provide the learner a piece of information, so that the students are able to enhance their skills, such as communication skill, empathy, building rapport, and showing concern. Students constantly received feedback throughout their learning in IMU, therefore the learners expected the feedback from SP should intended to enhance their learning and promote acquisition of skills. Few students expressed that they appreciated constructive feedback, which focused more on feeling from a patient's perspective, questioning skills, empathy, verbal and non-verbal communication skill. While, the students supposed that no value were gained from non-specific and general feedback (e.g. overall good, not bad). While, another interesting message conveyed by the student group was that SP feedback actually did not make sense for their learning until year two of study, when the medical trainees started to be more aware about the purpose of SP-based teaching and learning session.

\section{Fairness}

Smith et al., (2015) viewed SPs as "examination question" in performance-based assessment, thus a crucial element in the assessment, which referred to 
OSCE being the principle of standardization. Smith et al., (2015) expressed that the standardization is the consistency (reliability) and accuracy (validity) of their performance over time and between trainees so that each trainee is given the same fair and equal chance. Students perceived that non-standardization in role portrayal as well as diverse in quality of SP feedback impacted the fairness along their journey in University. Furthermore, students were concerned about the consistency and standardization in clinical examination because it impacted the fairness of the examination, which directly impacted the students' performance, result and progression. Students indicated that consistency as the individual SP had similar respond toward every student. Participants from student group highlighted that the inconsistency experiences included changed script content, accelerate or "under" portrayed physical symptoms such as pain, and non-verbal communication such as tone of voice and eye contact. While, student viewed that standardization apply to multiple SPs, portraying the same character as instructed by the lecturer. Students expressed that the lecturer should have role play with individual SPs before the real session. On the other hand, students supposed constructive feedback was from a feeling from a patient's perspective, specific, honest, and open. Students expressed that every student should receive constructive feedback from SP.

Another interesting result discussed was about prompting student during OSCE. SP who was hinting student, giving cues to student, answer more than the stated instruction were considered as prompting. Students emphasized that prompting should not occur during OSCE, because this conduct seriously impacted the fairness in examination.

\section{Limitation of the study}

This research did not represent all types of SP program and the researcher acknowledge that the research findings do not make for general conclusion related to the purpose.

\section{CONCLUSION}

Training SP for both realistic portrayals of the character and feedback is essential to optimize an SPbased simulation session. Additionally, standardization among the SP is crucial during OSCE to minimize biases.

Based on the findings of the study, improvement of the SP performance (authenticity of role portrayal and quality of SP feedback) as well as calibration of SP performance were highlighted. Hence, training is the key recommendation in this study. Firstly, training of role portrayal using four stage model which is helpful in improving the realistic portrayal of role as well as standardized SP performance is necessary. Secondly, training focus on enhancement in authenticity for role portrayal assist the SPs in creation of a more realistic character. Lastly, training must be based on giving quality SP feedback.

\section{Conflict of Interests}

The authors declare that they have no conflict of interest.

\section{ACKNOWLEDGEMENT}

The authors are thankful to the institutional authority for completion of the work.

\section{REFERENCES}

Beigzadeh, A., Bahmanbijari, B., Sharifpoor, E. \& Rahimi, M. (2016). Standardized patients versus simulated patients in medical education: are they the same or different. Journal of Emergency Practice and Trauma, 2(1), pp 25-28.

Bokken, L., Linssen, T., Scherpbier, A., Van Der Vleuten, C. \& Rethans, J.J. (2009). Feedback by simulated patients in undergraduate medical education: a systematic review of the literature. Medical Education, 43(3), pp 202-210.

Bressmann, T. \& Eriks-Brophy, A. (2012). Use of simulated patients for a student learning experience on managing difficult behaviour in speech-language pathology contexts. International Journal of Speech-language Pathology, 14(2), pp 165-173.

Brookhart, S.M. (2017). How to give effective feedback to your students. $\left(2^{\text {nd }}\right.$ ed). United State, US: ASDC.

Dudley, F. (2012). The simulated patient handbook: a comprehensive guide for facilitators and simulated patients. United Kingdom, UK: Radcliffe Publishing Ltd. 
Gamble, A. Bearman, M. \& Nestel, D. (2016). A systematic review: children \& adolescents as simulated patients in health professional education. Advance in Simulation, 1(1), pp 1-16.

Nestal, D. \& Bearman, M. (2015). Introduction to simulated patient methodology. in Nestel, D. \& Bearman, M. (Ed.), Simulated Patient Methodology: Theory, Evidence and Practice (pp. 1-4). British, UK: John Wiley \& Sons Ltd.

Onari, M. J., Pampaloni, F. \& Multak, N. (2012). What is a standardized patient? InWilson, L. \& Rockstraw, L. (2012). Human Simulation for Nursing and Health Professions. United State, US: Springer Publishing Company.

Quail, M., Brundage, S.B., Spitalnick, J., Allen, P.J. \& Beilby, J. (2016). Student self-reported communication skill, knowledge and confidence across standardized patient, virtual and traditional clinical learning environments. $B M C$ Medical Education, 16 (73), pp 1-12.

Smith, C.M., Edlington, T.L., Lawton, R. \& Nestel, D. (2015). Simulated patient methodology and assessment. in Nestel, D. \& Bearman, M. (Ed.), Simulated Patient Methodology: Theory, Evidence and Practice (pp. 39-45). British, UK: John Wiley \& Sons Ltd.

Williams, B. \& Song, J.J.Y. (2016). Are simulated patient effective in facilitating development of clinical competence for healthcare students? a scoping review. Advance in Simulation, pp 1-9.

Wisborg, T., Guttorm, B., Brinchmann-Hansen, A. \& Hansen, K.S. (2009). Mannequin or standardized patient: participants' assessment of two training modalities in trauma team simulation. Scandinavian Journal of Trauma, Resuscitation and Emergency Medicine, 17 (59), pp 1-4. 